\title{
RAZGLEDI
}

\section{UČINKOVITOST SOCIALNEGA VPLIVANJA PRI OKOLJSKEM OZAVEŠČANJU IN VEDENJU V POVEZAVI Z VODO}

\author{
AVTORICA \\ dr. Katarina Polajnar Horvat \\ Znanstvenoraziskovalni center Slovenske akademije znanosti in umetnosti, Geografski inštitut Antona Melika, \\ Gosposka ulica 13, SI - 1000 Ljubljana, Slovenija; katarina.polajnar@zrc-sazu.si
}

DOI: $10.3986 / G V 89202$

UDK: 911.3:628.1.033:502.12

COBISS: 1.01

\section{IZVLEČEK}

Učinkovitost socialnega vplivanja pri okoljskem ozaveščanju in vedenju v povezavi z vodo Spodbujanje okoljske ozaveščenosti in spreminjanje okoljskega vedenja sta koncepta, ki v sodobnih razpravah čedalje pogosteje prihajata v ospredje in predstavljata temelj trajnostno naravnane družbe. Človek namreč s svojim razmišljanjem in delovanjem vsakodnevno degradira pitno vodo kot naravno dobrino ter s tem intenzivno vpliva na njeno razpoložljivost in kakovost. Ena od možnih rešitev je uporaba metod socialnega vplivanja, skaterimi spodbujamo spremembo miselnosti in vedenja. V prispevku se tako ukvarjamo z vprašanjem, $v$ kolikšni meri so omenjene metode uspešne pri podpiranju človekovih okoljevarstvenih teženj in spremembi vedenja $v$ povezavi z vodo. Usmerjeno informiranje in izobraževanje, pisna zaobljuba, opomniki in nagrajevanje so se izkazale kot uspešen pristop. Poleg tega se je kot učinkovit medij za njihovo uporabo izkazal svetovni splet, saj zagotavlja dostop do velikega števila ljudi, hkrati pa omogoča uporabo metod socialnega vplivanja, prilagojenih vsakemu posamezniku glede na njegove lastnosti in potrebe.

\section{KLJUČNE BESEDE}

okoljska geografija, okoljsko vedenje, ozaveščenost, socialno vplivanje, voda

\begin{abstract}
The efficacy of social influence in environmental awareness and behaviour regarding water

The concepts of encouraging environmental awareness and changing environmental behaviour are gaining recognition in current discussions and are the foundation of a sustainably-oriented society. People's mentality and daily activity degrade drinking water as a natural resource, which profoundly affects its availability and quality. One of the possible solutions to this is the use social influence methods that help change mentalities and behaviour. The article explores to what degree these methods can be successful in supporting man's environmental protection tendencies and in changing behaviour regarding water. Directed information and education, commitments, reminders and rewards have shown to be a successful approach. The internet has also proven to be an efficient medium, as it can reach a great number of people, while also enabling the use of social influence methods that can be adjusted to each individual according to their characteristics and needs.
\end{abstract}

KEY WORDS

environmental geography, environmental behaviour, awareness, social influence, water

Uredništvo je prispevek prejelo 10. julija 2017. 


\section{Uvod}

Večina okoljskih izzivov, s katerimi se soočamo, so posledica človekovega negativnega okoljskega vedenja (Gardner in Stern 2002; DuNann Winter in Koger 2004; Vlek in Steg 2007). Že vse od sedemdesetih let preteklega stoletja se raziskovalci ukvarjajo s preučevanjem različnih pristopov za spodbujanje okolju prijaznega vedenja in posledično zmanjševanje negativnih vplivov na okolje, ki jih s skupnim imenom imenujemo socialno vplivanje. Sprava so akcije za spodbujanje okoljske ozaveščenosti temeljile na poenostavljeni domnevi, da je pomanjkanje znanja ena izmed najpogostejših ovir za udejanjanje okolju prijaznega vedenja (Kollmuss in Agyeman 2002). Vendar se je kmalu izkazalo, da izobraževanje, pri katerem posamezniku zgolj posredujemo izbrane informacije, ni vedno dovolj učinkovito za spremembo le-tega (Staats, Wit in Midden 1996; Shultz 1999: po Abrahamse in Matthies 2013). Izobraževanje namreč pozitivno vpliva na spremembo posameznikovih prepričanj in stališč, le v manjši meri pa vpliva na spreminjanje posameznikovih vrednot in norm ter s tem na spremembo v okoljski zavesti in v vedenju (Polajnar Horvat 2015). Raziskava (Staats, Wit in Midden 1996) o učinkovitosti obsežne državne akcije v Združenih državah Amerike, katere namen je bil zviševanje ozaveščenosti o podnebnih spremembah in možnih ukrepih za njihovo blaženje, je tako na podlagi anket pred in po izvedenih akcijah sicer pokazala izboljšanje znanja o podnebnih spremembah in spremembo stališč v pozitivnem smislu, vendar pa pri tem ni prišlo do spremembe v vedenju, predvsem zaradi ovir kot je nepripravljenost odrekanju bodisi udobja, časa ali denarja. Ljudje imajo torej do okolja pogosto odtujen odnos in nemalokrat se znajdejo v primežu ostalih neokoljskih prioritet oziroma delujejo po načelu: "Nobenega smisla nima, da po svojih najboljših močeh skrbim za okolje, če tega ne počnejo tudi drugi« (Polajnar Horvat 2015). Svoje vloge in pomena lastnih dejanj se ne zavedajo, ob tem pa se nemalokrat tudi okoljsko ozaveščeni ljudje ujamejo v zanko kolektivne okoljske apatije (Polič 2002). Hkrati so ljudje pogosto preveč kratkoročno usmerjeni, da bi razmišljali o dolgoročnih posledicah svojega vedenja za naš planet, zato so pogosto premalo okoljsko aktivni (Polajnar Horvat 2012).

Na podlagi ugotovitve, da zgolj podajanje splošnih informacij, usmerjenih v širšo populacijo, brez vnaprej prilagojenega pristopa, pogosto ne pripelje do ustreznih rezultatov, so raziskovalci razvili več metod socialnega vplivanja za spodbujanje okolju prijaznega vedenja.

V raziskavi se navezujemo na nekoliko preoblikovano delitev Messick in Brewerja (1983), ki ločujeta med informacijskimi in strukturnimi strategijami. Na eni strani so informacijske strategije, s katerimi spreminjamo posameznikovo motivacijo, zaznavanje, znanje in norme oziroma ozaveščenost, ne da bi ob tem spreminjali zunanje okoliščine, v katerih so vedenjske odločitve sprejete. Na drugi strani so strukturne strategije (Steg in Vlek 2009), s katerimi spreminjamo okoliščine, v katerih se sprejemajo vedenjske odločitve oziroma v katerih se vedenje uresničuje (Messick in Brewer 1983; Steg in Vlek 2009). Različne vrste strategij, tako informacijske kot strukturne, se soočajo z različno stopnjo uspešnosti, pri čemer so uspešnejši tisti pristopi, ki so sestavljeni iz več različnih vrst strategij, bodisi izbranih informacijskih ali strukturnih, bodisi kombinacije obeh, saj se lahko na ta način uspešneje prilagodijo tako ljudem kot danim razmeram (Abrahamse in Matthies 2013). Tako je bistvenega pomena, da dobro poznamo in hkrati razumemo, kaj je tisto, kar vodi ljudi k negativnemu odnosu do okolja ter okolju neprijaznemu delovanju, saj smo le na ta način lahko ustrezno usposobljeni za načrtovanje strategij, ki pospešujejo razvoj okoljske ozaveščenosti in vedenja ter oblikovanje politik, ki to spodbujajo.

Osrednji namen pričujočega dela je ugotoviti ali lahko z izbranimi metodami socialnega vplivanja dosežemo dejanske spremembe v okoljski ozaveščenosti in vedenju v smeri trajnosti na primeru potrošnje vode v gospodinjstvu ter katere metode so pri tem uspešnejše. Zato smo izvedli raziskavo, pri kateri smo posameznikom, ki so se prostovoljno vključili v skupino Ekologičen, tako z informacijskimi kot tudi strukturnimi strategijami, skušali dvigniti okoljsko ozaveščenost v povezavi z rabo vode ter spremeniti njihovo vedenje v smeri trajnosti. Pred in po izvedbi omenjenega socialnega vplivanja smo s pomočjo obsežnega anketiranja merili dejanske spremembe v vedenju. 


\section{Metode socialnega vplivanja}

Obstaja več različnih opredelitev socialnega vplivanja, ki se razlikujejo glede na vsebino in vpliv, ki ga ima posamezna metoda na vedenja (De Young 1993; Vlek 2000; Gardner in Stern 2002; Geller 2002). Kot rečeno smo v raziskavi uporabili nekoliko preoblikovano delitev strategij Messicka in Brewerja (1983), ki ločujeta med informacijskimi in strukturnimi strategijami. Informacijske strategije lahko opredelimo tudi kot mehke ukrepe, kamor med drugim uvrščamo izobraževanje, opominjanje, predhodno določitev cilja, zaobljube, povratne informacije in podobno. Po drugi strani pa lahko strukturne strategije opredelimo kot trde ukrepe (Abrahamse in Matthies 2013), ki zahtevajo spremembe bodisi $\mathrm{v}$ tehničnem smislu bodisi $\mathrm{v}$ spodbudah. Med učinkovite informacijske strategije sodi izobraževanje po meri, katerega glavni namen je čim bolj učinkovito in usmerjeno posredovanje informacij in s tem spodbujanje njegove pozornosti in zainteresiranosti. Pri tej metodi posameznik prejme posebej njemu prilagojene informacije (Kreuter s sodelavci 1999). Človek je razumno bitje, ki sistematično izbira med vrstami informacij, ki jih prejme. Zato je bolj smiselno, da posameznik prejme le zanj bistvene informacije, kot pa da ga obremenjujemo s preveliko količino splošnih informacij. Poleg posredovanja bolj verodostojnih informacij, so se strokovnjaki usmerili v krepitev povezav med stališči in vedenjem. Nekatere raziskave so pokazale, da, kljub ustreznim stališčem in znanju, ta neposredno ali samodejno ne vodijo k okolju prijaznemu vedenju (Gardner in Stern 2002). Ljudje se vselej ne vedejo tako, kot jim narekujejo njihova okoljska zavest in ostali dejavniki vedenja, čeprav vedo, na kakšen način je treba delovati in da ni nikakršnih ovir, ki bi preprečevale okolju prijazno vedenje. Razvile so se strategije, s katerimi posameznika opozarjamo na to, kaj mu narekuje njegova okoljska zavest. K temu ga spodbujamo na različne načine, med katerimi izpostavljamo predhodno zavezo in spodbudo. Zaveza je ustna ali pisna zaobljuba oziroma zaprisega za spremembo vedenja. Običajno jo uporabljamo v povezavi s predhodno določitvijo cilja (na primer zaveza o zmanjšanju porabe vode za $5 \%$ ). Poznamo dve vrsti zaveze. $\mathrm{Na}$ eni strani gre za osebno zavezo samemu sebi, s katero spodbudimo posameznikove osebne norme oziroma moralne obveze, na drugi pa za javno zavezo, s katero spodbudimo posameznikove subjektivne norme (pričakovanja posameznikovih pomembnih vplivnežev), ki postanejo odločilen dejavnik okoljskega vedenja (Abrahamse in Matthies 2013). Po mnenju nekaterih raziskovalcev vpliva zaveza na spremembo vedenja z zniževanjem spoznavnega neskladja (cognitive dissonance) (Festinger 1957), ki nastane v primeru, ko posameznikova prepričanja ali stališča niso skladna $z$ njegovim vedenjem. Če se posameznik zaveže $\mathrm{k}$ udejanjenju izbranega vedenja brez kakršnekoli zunanje prisile ali morebitne nagrade, v večji meri tudi dejansko spremeni svoje vedenje. Navdaja ga namreč občutek samostojne odločitve, nastale na podlagi lastnih notranjih motivov (Gardner in Stern 2002). Spodbuda je način informiranja posameznikov, običajno s kratkimi sporočili, $s$ katerimi usmerjamo na določeno vedenje $\mathrm{v}$ danih razmerah oziroma opozarjamo nanj (Abrahamse in Matthies 2013). Gre za enostavno opominjanje o primernem vedenju (na primer »Zapiraj vodo med umivanjem zob!«). Njihova uporaba temelji na predpostavki, da je posameznik že ponotranjil pozitivna stališča oziroma pozitivne namere za okolju prijazno vedenje, vendar mu za njegovo udejanjenje primanjkuje določena spodbuda. S spodbudami presežemo samodejni pojav okolju neprijaznega vedenja, ki se običajno pojavi zaradi posameznikovih izrazitih navad (Abrahamse in Matthies 2013). Posameznika $\mathrm{k}$ dejanjem najlaže pripravimo tako, da ga k temu nagovorimo. Namen sloganov, kot so »Porabi manj!«, ni izobraževanje, temveč opozarjanje ljudi, da se bolj primerno vedejo. Na ta način presežemo notranje ovire, denimo pozabljanje ali lenobo, ki posamezniku preprečujejo udejanjanje okolju prijaznega vedenja (Gardner in Stern 2002). Raziskave kažejo, da so bolj kot splošne spodbude, ki se pojavijo naključno, učinkovite ciljne skupini prilagojene konkretne spodbude, oblikovane na vljuden način ter posredovane na primernem mestu ob skrbno načrtovanem času (Gardner in Stern 2002; Abrahamse in Matthies 2013). Kljub vsemu nekateri opozarjajo na razmeroma kratkoročen vpliv spodbud pri okoljskem vedenju (na primer Bell s sodelavci 2001) ter na dejstvo, da so spodbude učinkovitejše pri udejanjanju enostavnejših vedenj (Geller, Wineet in Everett 1982). 
V primerih, ko je okolju prijazno vedenje povezano z večjimi odrekanji (v smislu večjih stroškov, večje porabe časa, večjega napora ali zmanjšanje udobja ...) ali oteženo zaradi določenih zunanjih ovir, ki preprečujejo njegovo izvajanje, lahko z izbranimi strukturnimi strategijami spreminjamo spodbude, na podlagi katerih se vedenje udejanja (Steg in Gifford 2008). Na ta način krepimo motivacijo za okolju prijazno vedenje in ga skušamo narediti privlačnejšega (Thøgersen 2005). Namen strukturnih strategij je torej neposredno spreminjanje spodbud, s čimer posredno vplivamo na posameznikovo zaznavanje ter motivacijske dejavnike in posledično na njegovo vedenje (Steg in Vlek 2009). Obstaja več načinov spreminjanja vedenjskih spodbud: razpoložljivost in kakovost izdelkov ter storitev, uveljavitev zakonskih predpisov in cenovna politika (Steg in Vlek 2009; Bolderdijk, Lehman in Geller 2013). Razpoložljivost in kakovost izdelkov ter storitev lahko spremenimo s fizičnimi, tehničnimi in organizacijskimi spremembami. Na ta način lahko dosežemo, da okolju neprijazno vedenje postane manj privlačno ali celo onemogočeno (primer je zaprtje ožjega mestnega središča Ljubljane za motorni promet), okolju prijazno vedenje pa privlačnejše, kot je bila na primer nedavna uveljavitev zabojnikov za ločevanje embalaže in papirja v vsakem ljubljanskem gospodinjstvu. Primer učinkovite spremembe spodbud je tudi nakup okolju prijaznih izdelkov, kot je nakup energetsko varčnega hladilnika, s čimer v precejšnji meri zmanjšamo okoljski vpliv; storitev, ki jo izdelek opravlja, pa ostaja nespremenjena. Naslednja možnost spreminjanja vedenjskih spodbud so zakonski predpisi (na primer z zakonom prepovedano odlaganje odpadkov v naravi, ki je tudi kazensko sankcionirano), na podlagi katerih se sprejemajo uredbe, v katerih so jasno opredeljeni ukrepi, s katerimi sankcioniramo kršitelje. Spodbude okoljskega vedenja lahko spreminjamo tudi s cenovno politiko. Uspešni metodi cenovne politike sta zvišanje stroškov okolju neprijaznega vedenja na eni strani in znižanje stroškov vedenju, ki je okolju prijazno.

Pri strukturnih strategijah gre na nek način za nagrajevanje okolju prijaznih dejanj in kaznovanje neprijaznih (Steg in Vlek 2009). Razlikujemo nagrade in kazni, katerih teoretsko ozadje temelji na dejstvu, da smo ljudje motivirani na podlagi obetov, ki sledijo po končanem dejanju, kar $\mathrm{z}$ drugimi besedami pomeni, da stvari počnemo zaradi pozitivnih posledic, izogibamo pa se početju tistih z negativnimi posledicami (Bolderdijk, Lehman in Geller 2013). Nagrade so prijetne posledice, s katerimi spodbujamo okolju prijazno vedenje, medtem ko so kazni neprijetne posledice, s katerimi sankcioniramo okolju neprijazno vedenje (Bolderdijk, Lehman in Geller 2013). Po Gellerjevem (2002) mnenju so pri spodbujanju okolju prijaznega vedenja nagrade učinkovitejše kot kazni, saj so povezane s pozitivnimi čustvi in stališči, ki podpirajo vedenjske spremembe. Na drugi strani so kazni manj učinkovite, saj porajajo negativna čustva in stališča, izogibalno vedenje, $v$ določenih primerih pa lahko povzročijo celo odpor javnosti. Pri posamezniku lahko ustvarijo občutek izgube svobode, kar se izrazi v delovanju, ki je nasprotno z zaželenim. Tovrstni proces imenujemo psihološki odpor (psychological reactance) (Brehm 1966) oziroma protinadzor (countercontrol) (Skinner 1953). V zadnjem času se pri spodbujanju ustreznega okoljskega vedenja uveljavljajo družbeni mediji. So nova oblika spletnih medijev, ki se od tradicionalnih razlikujejo v tem, da omogočajo večjo povezanost med uporabniki. Opredelimo jih lahko kot skupek spletnih aplikacij, ki omogočajo ustvarjanje in izmenjavo uporabniških vsebin (Kaplan in Haenlein 2010). So vsesplošno dostopni in omogočajo prilagodljive tehnike medsebojnega komuniciranja. Njihov začetek lahko postavimo v leto 1971, ko je bilo poslano prvo sporočilo prek elektronske pošte. Od takrat se je naše povezovanje s svetom le še stopnjevalo. Medsebojna komunikacija prek svetovnega spleta ni bila še nikoli tako enostavna in široko dostopna kot dandanes (O’Dell 2011). Za družbene medije so značilne naslednje lastnosti, zaradi katerih so postali priljubljen in nepogrešljiv del našega vsakdana (Mayfield 2008; Bradley 2010): medsebojno sodelovanje, odprtost, komunikacija, skupnost, povezanost, večpredstavnost, transparentnost, neodvisnost, nepredvidljivost.

\section{Metode}

Raziskavo o učinkovitosti metod socialnega vplivanja pri spreminjanju ozaveščenosti in vedenja v povezavi z vodo smo izvedli na območju Mestne občine Ljubljana med 11. marcem in 11. decem- 
brom 2010. Obsegala je dva obsežnejša sklopa: anketiranje in socialno vplivanje. Raziskava je potekala na spletnem portalu Ekologičen (medmrežje 1). Prvo obdobje (11. marec-5. maj 2010), je obsegalo osebno in spletno anketiranje o rabi vode v gospodinjstvu. Uspešno opravljenih je bilo 690 anket. Namen je bil ugotoviti, kakšno znanje in kakšne navade posedujejo anketiranci glede preučevane tematike. Sodelujoče $\mathrm{v}$ omenjeni anketi smo povabili $\mathrm{v}$ nadaljnjo raziskavo, ki se je prav tako odvijala prek spletnega portala Ekologičen (medmrežje 1), in sicer z vključitvijo v spletno skupino Ekologičen, katere namen je bil redno spodbujanje članov k varčnemu vedenju v gospodinjstvu. Žal je bilo med anketiranci majhno zanimanje za vključitev v skupino; za to se jih je odločilo zgolj 95 . Med temi je bilo 32,6\% moških in $67,4 \%$ žensk. Glede na starostno strukturo so prevladovali stari med 25 in 44 let (57,9\%), sledili so stari med 45 do 64 let $(24,2 \%)$, stari med 15 in 24 let (13,7\%) in stari več kot 65 let $(4,2 \%)$. Udeležence skupine Ekologičen smo spodbujali $\mathrm{k}$ varčevanju $\mathrm{z}$ vodo na dva načina: $\mathrm{z}$ informacijskimi in $\mathrm{s}$ strukturnimi strategijami. V okviru informacijskih strategij smo največji poudarek namenili usmerjenemu informiranju o okoljevarstveni problematiki in značilnostih vedenj v povezavi $\mathrm{z}$ vodo ter izobraževanju v obliki nasvetov. Informiranje in izobraževanje, ki je potekalo med 24. majem in 24 . novembrom 2010, smo prilagodili preučevani skupini in s tem dosegli večjo učinkovitost. Oblikovali smo šest nasvetov (preglednica 1), pri čemer je uvodni nasvet vključeval tudi podrobnejše informacije o preučevani problematiki. Vsak nasvet vsebuje njegovo podrobnejšo predstavitev in navodila za varčno vedenje $\mathrm{v}$ povezavi $\mathrm{z}$ vodo. Poleg tega smo $\mathrm{z}$ usmerjenimi osebnimi nagovori skušali udeležence še dodatno motivirati k varčevanju. Vsi nasveti so bili ob izbranih datumih (preglednica 1) poslani članom skupine prek elektronske pošte, poleg tega pa smo jih sočasno objavili tudi na spletnem portalu Ekologičen (medmrežje 1) ter na njihovi Facebookovi strani.

Preglednica 1: Razrez nasvetov za varčno vedenje v povezavi z vodo v gospodinjstvu.

\begin{tabular}{ll} 
24.5.2010 & 1. Netrajnostni sodobni način življenja in raba vode v gospodinjstvu. \\
\hline 1.1 Kaj lahko naredimo sami? \\
\hline 7.6 .2010 & 2. Peremo in pomivamo na EKOLOGIČEN način. \\
\hline 14.6 .2010 & 3. Umivajmo se z glavo. \\
\hline 21.6 .2010 & 4. Vsaka kapljica vode šteje, šteje, šteje ... \\
\hline 28.6 .2010 & 5. Koliko vode odteče v prazno? \\
\hline
\end{tabular}

V oktobru 2010 smo v okviru projekta INCOME izdelali spletni kviz z naslovom »Ali znam varčevati z vodo? (medmrežje 2), katerega namen je ozaveščanje in izobraževanje ljudi o rabi vode oziroma preverjanje znanja o rabi vode. Člane skupine smo prek elektronske pošte in družbenega omrežja Facebook povabili k reševanju kviza in s tem k preverjanju znanja, ki so ga pridobili z nasveti o rabi vode.

Pred samim začetkom usmerjenega informiranja in izobraževanja smo uporabili metodo pisne zaobljube kot posameznikove obveze, da bo v naslednjih šestih mesecih deloval okolju prijazno. Uporabili smo metodo osebne zaobljube in na ta način vplivali na posameznikovo osebno normo, s čimer se počuti obvezanega, da deluje okolju prijazno. Vsakemu članu smo prek elektronske pošte poslali dopis z zaobljubo v elektronski obliki in podrobnejša navodila za uporabo. Udeležence smo prosili, naj si zaobljubo natisnejo na papir, se prostovoljno odločijo o njenem podpisu in nam v 14 dneh posredujejo odločitev.

$\mathrm{V}$ dosedanjih raziskavah socialnega vplivanja na področju spreminjanja okoljskega vedenja so se opomniki izkazali kot zelo učinkovita metoda (Gardner in Stern 2002). Člane skupine smo z izbranimi opomniki, ki so jih prejeli prek elektronske pošte, po dveh in petih dneh od objave posamezne novice, spominjali na okolju prijazno vedenje v gospodinjstvih. Poleg tega smo opomnike sočasno objavljali na Facebook strani skupine Ekologičen. 
Poleg informacijskih strategij smo uporabili tudi strukturne strategije, in sicer nagrajevanje, ki je potekalo trikrat. Gre za teorijo družbene izmenjave, po kateri naj bi se oseba, ki nekaj dobi, čutila dolžno nekaj tudi vrniti. Podarili smo sto okolju prijaznih nakupovalnih vrečk, deset solarnih polnilcev podjetja Ekodom in bioresonančno terapijo v Energijski točki. Po končanem socialnem vplivanju smo $\mathrm{z}$ udeleženci skupine Ekologičen ponovili anketiranje o rabi vode v gospodinjstvu in primerjali rezultate.

Pred in po uporabi izbranih metod smo merili vedenja $\mathrm{v}$ povezavi $\mathrm{z}$ vodo $\mathrm{s}$ šestnajstimi spremenljivkami (preglednica 2) na tristopenjski (da/delno/ne) ali na petstopenjski ordinalni lestvici.

Preglednica 2: Spremenljivke za merjenje vedenja v povezavi $z$ vodo v gospodinjstvu.

1. Ali ste v zadnjih šestih mesecih zmanjšali porabo vode?

2. Kako pogosto pustite teči vodo, medtem ko si umivate zobe?

3. Kako pogosto pustite teči vodo, medtem ko se milite med prhanjem?

4. Kako pogosto pustite teči vodo, medtem ko ročno pomivate posodo?

5. Kako pogosto pri pitju uporabite povsem čist kozarec?

6. Kolikokrat na teden uporabljate pralni stroj, ko je/ni poln?

7. Kolikokrat na teden uporabljate pomivalni stroj, ko je/ni poln?

8. Kolikokrat na teden se prhate/kopate?

9. Koliko časa se prhate? ( 1 - več kot 15 minut, 2 - od 11 do 15 minut, 3 - od 6 do 10 minut, 4 - od 3 do 5 minut, 5 - manj kot 3 minut)

10. Ali ste $\mathrm{v}$ zadnjih šestih mesecih $\mathrm{v}$ prho dali namestiti zračnik za nizek pretok, ki vodi primeša zrak?

11. Ali ste v zadnjih šestih mesecih vgradili ekološki straniščni splakovalnik?

12. Ali ste $\mathrm{v}$ zadnjih šestih mesecih preverili, ali v stanovanju kje uhaja voda?

13. Ali ste $\mathrm{v}$ zadnjih šestih mesecih tisto posodo, ki ste jo pomivali ročno, pomivali v pomivalnem koritu, pod tekočo vodo pa jo samo splaknili?

14. Ali ste v zadnjih šestih mesecih zmanjšali rabo čistil, pralnih praškov, mehčalcev ali kozmetike?

15. Ali ste v zadnjih šestih mesecih v straniščno školjko metali stvari, ki bi lahko zamašile odtok vode ali zastrupile vodo?

16. Ali ste $\mathrm{v}$ zadnjih šestih mesecih vgradili individualni števec za merjenje porabe vode v stanovanju?

\section{Rezultati in razprava}

Po končanem šestmesečnem obdobju uporabe izbranih metod socialnega vplivanja za spodbujanje okolju prijaznega vedenja $\mathrm{v}$ povezavi $\mathrm{z}$ vodo so udeleženci izrazili pozitivnejše delovanje kot pred izvedbo socialnega vplivanja, za kar se je v primerjavi $\mathrm{z}$ obdobjem pred izvedbo socialnega vplivanja opredelila šestina $(14,7 \%)$ več. Delež tistih, ki so se opredelili negativno se je znižal za dobro dvajsetino $(6,3 \%)$ (preglednica 3). Friedmanov test, s katerim smo ugotavljali statistično pomembnost razlik med obema merjenjema, je pokazal statistično značilno razliko pri spremenljivki o varčevanju z vodo.

Pitna voda je bogastvo, ki ni neizčrpno. Malokdo razmišlja o tem, koliko vode porabi za posamezno gospodinjsko opravilo in koliko bi jo lahko privarčeval že z majhno spremembo svojega vedenja. Če bi vsak prebivalec v Sloveniji zmanjšal dnevno porabo vode za en liter, bi v letu dni prihranil okrog milijon kubičnih metrov dragocene tekočine, brez katere ni življenja (Burja 2007). Če zapremo pipo 
Preglednica 3: Spremembe v vedenju pri rabi vode (legenda: 1 - ne, 2 - delno, 3 - da) (Anketa o rabi vode... 2010; Spletna anketa o rabi vode... 2010).

\begin{tabular}{llccccccc}
\hline stališče & čas & $\begin{array}{c}\text { število } \\
\text { anketirancev }\end{array}$ & 1 & 2 & 3 & $\overline{\mathrm{x}}$ & SD & $\begin{array}{c}\text { Friedmanov } \\
\text { test }\end{array}$ \\
\hline $\begin{array}{l}\text { Ali ste v zadnjih } \\
\text { sestih mesecih } \\
\begin{array}{l}\text { zmanjšali porabo } \\
\text { vode? }\end{array}\end{array}$ & $\begin{array}{l}\text { pred } \\
\text { vplivanjem }\end{array}$ & 95 & $8,4 \%$ & $22,1 \%$ & $69,5 \%$ & 2,61 & 0,64 & $\chi^{2}=5,452$ \\
\cline { 2 - 8 } & po vplivanju & 95 & $2,1 \%$ & $13,7 \%$ & $84,2 \%$ & 2,80 & 0,49 & $\mathrm{p}<0,01$ \\
\hline
\end{tabular}

vselej, kadar vode ne potrebujemo, lahko prihranimo kar do 80.000 litrov vode na leto, kar lahko primerjamo s količino vode, s katero napolnimo plavalni bazen (Burja 2007). Zato nas je zanimalo, v kolikšni meri so udeleženci spremenili svoje vedenje, in sicer v kolikšni meri so začeli zapirati vodo (preglednica 4), ko je pri posameznih opravilih ne potrebujejo. Udeleženci so po izvedbi socialnega vplivanja $\mathrm{v}$ največji meri začeli zapirati vodo medtem, ko si umivajo zobe in ko se milijo med prhanjem; sprememba v srednjih vrednostih $(\Delta \overline{\mathrm{x}})$ pri obeh vedenjih je 0,19 . Pri ročnem pomivanju posode je bila sprememba $\mathrm{v}$ srednjih vrednostih 0,12 . V najmanjši meri pa so spremenili vedenje v povezavi $\mathrm{z}$ uporabo povsem čistega kozarca, saj je sprememba $v$ srednji vrednosti zgolj 0,07 . Friedmanov test je pokazal statistično značilno razliko $\mathrm{v}$ trditvah pred in po merjenju zgolj pri vedenju povezanem $\mathrm{z}$ zapiranjem vode med opravili.

Udeležence smo v okviru izbranega vplivanja ozaveščali o tem, kako pomembno je, da pri pranju perila ali pomivanju posode s pomočjo strojev pazimo na količino perila ali posode, ki ju želimo oprati. Le malokrat namreč razmišljamo o tem, koliko vode potrošimo, $\mathrm{v}$ kolikor peremo ali pomivamo $\mathrm{z}$ na pol praznimi aparati. Udeleženci so po izvedbi socialnega vplivanja po eni strani količino pranj s polnimi aparati povišali (preglednica 5); srednja vrednost pri uporabi polnega pralnega stroja je 2,88, pomivalnega pa 5,44. Po drugi strani pa so v precejšnji meri znižali količino pranj, ko stroji niso polni. Srednja vrednost pri uporabi delno polnega pralnega stroja je 1,36, pomivalnega pa 1,40. Poleg tega se je tudi zmanjšalo število udeležencev, ki pere in pomiva $\mathrm{z}$ delno polnimi gospodinjskimi aparati, kar je precej spodbuden podatek. Pri večini udeležencev se je sprememba vedenj izkazala kot statistično značilna, kar dokazuje izračunan Friedmanov test ob vsaki od preučevanih spremenljivk (preglednica 5). Nadalje nas je zanimalo, v kolikšni meri so udeleženci skupine Ekologičen spremenili svoje vedenje $\mathrm{v}$ povezavi z lastno higieno. Rezultati kažejo, da je količina prhanj ostala praktično enaka oziroma se je celo za malenkost povišala, medtem pa se je znižal čas prhanja, ki je bil po končanih metodah v povprečju manj kot 3 minute. Podobno kot prhanje je število kopanj ostalo enaka, prav tako se ni spremenilo število udeležencev, ki se kopajo. Izračunani Friedmanov test za vsako spremenljivko kaže na statistično neznačilne razlike $\mathrm{v}$ spremembi pričujočih preučevanih vedenj.

Pogosto se ne zavedamo, da lahko $\mathrm{z}$ različnimi ukrepi, ki ne zahtevajo pretiranega odrekanja udobju, $\mathrm{z}$ vodo privarčujemo. Tako nas je zanimalo, v kolikšni meri so udeleženci po izvedbi socialnega vplivanja izvedli različna dejanja, povezana $\mathrm{z}$ varčevanjem vode v svojem gospodinjstvu. Znotraj posameznih primerov smo vključili tudi nekatere manj običajne $\mathrm{z}$ namenom ugotoviti, s kakšno skupino ljudi in njihovih vedenj imamo opravka (preglednica 6). Po končnih metodah je dobra petnajstina $(7,4 \%)$ udeležencev dala $\mathrm{v}$ prho namestiti zračnik za nizek pretok, ki vodi primeša zrak, pri čemer je razlika statistično značilna $(\mathrm{p}<0,001)$, prav tako pa so trije udeleženci v zadnjih šestih mesecih vgradili ekološki straniščni splakovalnik $(\mathrm{p}>0,05)$. V primerjavi z deležem tistih, ki so pred metodami preverjali ali jim voda kje uhaja, se je ta povišal za slabo desetino $(21,4 \%)(p>0,05)$. Za dobro desetino $(13,1 \% ; p<0,001)$ se je povišal deleža tistih, ki so tisto posodo, ki so jo pomivali ročno, pomivali v pomivalnem koritu, pod tekočo vodo pa jo le splaknili, za slabo dvajsetino $(18,2 \%$; $<<0,001)$ pa se je povišal delež tistih, 


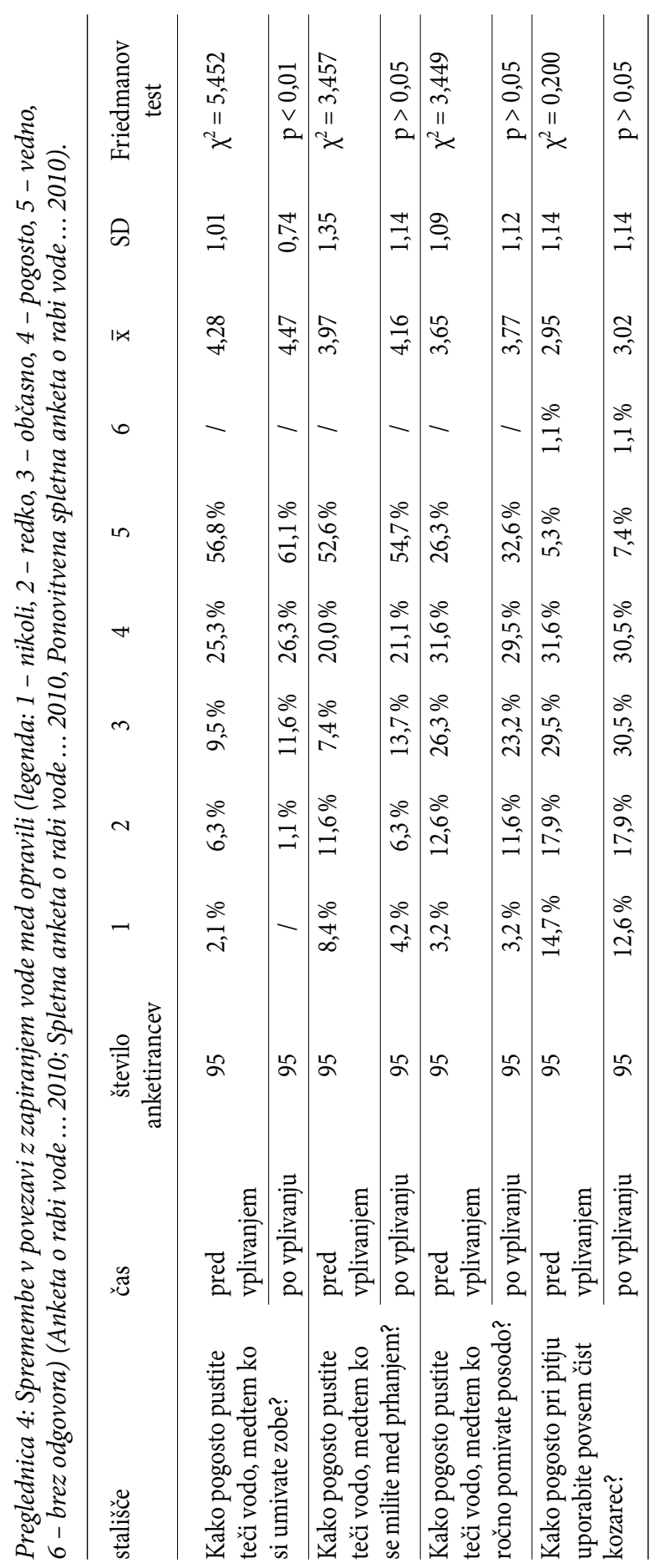


Preglednica 5: Spremembe v povezavi z rabo vode pri pranju perila in pomivanju posode (Anketa o rabi vode... 2010; Spletna anketa o rabi vode ... 2010; Ponovitvena spletna anketa o rabi vode ... 2010).

\begin{tabular}{|c|c|c|c|c|c|}
\hline stališče & čas & $\begin{array}{c}\text { število } \\
\text { anketirancev }\end{array}$ & $\overline{\mathrm{x}}$ & $\mathrm{SD}$ & $\begin{array}{c}\text { Friedmanov } \\
\text { test }\end{array}$ \\
\hline \multirow{2}{*}{$\begin{array}{l}\text { Kolikokrat na teden } \\
\text { uporabljate pralni } \\
\text { stroj, ko je poln? }\end{array}$} & pred vplivanjem & 67 & 2,76 & 1,57 & $\chi^{2}=1,588$ \\
\hline & po vplivanju & 67 & 2,88 & 0,96 & $p>0,05$ \\
\hline \multirow{2}{*}{$\begin{array}{l}\text { Kolikokrat na teden } \\
\text { uporabljate pralni } \\
\text { stroj, ko ni poln? }\end{array}$} & pred vplivanjem & 15 & 1,63 & 1,10 & $\chi^{2}=5,321$ \\
\hline & po vplivanju & 11 & 1,36 & 0,67 & $\mathrm{p}<0,01$ \\
\hline \multirow{2}{*}{$\begin{array}{l}\text { Kolikokrat na teden } \\
\text { uporabljate pomivalni } \\
\text { stroj, ko je poln? }\end{array}$} & pred vplivanjem & 77 & 4,68 & 1,88 & $\chi^{2}=11,571$ \\
\hline & po vplivanju & 77 & 5,44 & 1,41 & $\mathrm{p}<0,001$ \\
\hline \multirow{2}{*}{$\begin{array}{l}\text { Kolikokrat na teden } \\
\text { uporabljate pomivalni } \\
\text { stroj, ko ni poln? }\end{array}$} & pred vplivanjem & 22 & 2,80 & 0,44 & $x^{2}=4,000$ \\
\hline & po vplivanju & 5 & 1,40 & 0,89 & $\mathrm{p}<0,05$ \\
\hline
\end{tabular}

ki so zmanjšali uporabo kemičnih sredstev. Zmanjšal pa se je tudi delež tistih, ki v straniščno školjko mečejo stvari, ki bi lahko zamašile odtok (za 8,2 \%; p >0,05). Nazadnje smo udeležence povprašali še o tem, ali so $\mathrm{v}$ zadnjih šestih mesecih vgradili individualni števec za merjenje porabe vode v gospodinjstvu, pri čemer se je za pritrdilni odgovor izrekla dobra desetina (12,6\%) (preglednica 6).

\section{Sklep}

Rezultati vloge izbranih metod socialnega vplivanja, usmerjenega informiranja in izobraževanja, pisne zaobljube, opomnikov in nagrajevanja na dejavnike vedenja kažejo na njihovo precejšnjo uspešnost tako v pozitivnejšem odnosu do okolja, večji pripravljenosti za okolju prijazno vedenje kot tudi v ustreznejšem ravnanju samem. Kot uporabno se je usmerjeno informiranje in izobraževanje izkazalo pri krepitvi znanja, saj so posamezniki pokazali precej višjo stopnjo poznavanja preučevanih vsebin po izvedbi socialnega vplivanja. Poleg tega se je izkazalo kot uspešno tudi pri krepitvi zaznanega vedenjskega nadzora, torej posameznikovega lastnega občutka sposobnosti udejanjanja okolju prijaznega vedenja in prepričanja o razpoložljivosti sredstev za udejanjanje takšnega vedenja. Vzrok za omenjeno je najverjetneje v precejšnjem poudarku, ki smo ga pri socialnem vplivanju namenili seznanjanju udeležencev $\mathrm{z}$ relativno enostavnimi in drobnimi ukrepi $\mathrm{v}$ gospodinjstvu, $\mathrm{s}$ katerimi lahko pripomoremo k izboljšanju stanja okolja ter katere lahko $\mathrm{z}$ minimalnim naporom opravi vsak posameznik brez uporabe kakršnih koli dodatnih sredstev ali stroškov. S tem smo posameznikom omogočili precejšen preskok v odnosu do lastnih zmožnosti in samoučinkovitosti. Rezultati so hkrati pokazali spremembo v pripravljenosti za okolju prijazno vedenje ter v vedenju samem, kar kaže na to, da so metode socialnega vplivanja udeležence resnično spodbudile k ukrepanju. Kot uporabna se je izkazala tudi pisna zaobljuba, saj je bil odziv udeležencev nanjo zelo pozitiven. Hkrati so se kot uspešni izkazali tudi opomniki, saj se je ob njihovi objavi, še posebej na družbenem omrežju Facebook, pogosto razvila živahna razprava o tematiki. V nasprotju od ostalih pa se je kot manj uspešno izkazalo nagrajevanje, saj udeležencev osebnega anketiranja, še posebej tistih nezainteresiranih, ob njegovi najavi ni prepričalo k sodelovanju v raziskavi. 
Katarina Polajnar Horvat Učinkovitost socialnega vplivanja pri okoljskem ozaveščanju in vedenju ...

Eden izmed razlogov je morda tudi v tem, da so bile nagrade izključno okoljevarstvene narave in v tem oziru niso pritegnile širšega kroga ljudi, ki jih okoljska tematika zanima v manjši meri. Ugotovili smo, da splet predstavlja učinkovit medij za uporabo metod socialnega vplivanja. Nudi namreč možnost doseganja sorazmerno velikega števila ljudi, hkrati pa omogoča zagotavljanje metod socialnega vplivanja oziroma strategij, prilagojenih vsakemu posamezniku glede na njegove značilnosti in potrebe. $\mathrm{Z}$ us-

Preglednica 6: Spremembe pri posameznih dejanjih $v$ povezavi $z$ rabo vode (legenda: 0 - ne, 1 - da, 2 - brez odgovora) (Anketa o rabi vode ... 2010; Spletna anketa o rabi vode ... 2010, Ponovitvena spletna anketa o rabi vode... 2010).

\begin{tabular}{|c|c|c|c|c|c|c|c|c|}
\hline spremenljivka & čas & $\begin{array}{c}\text { število } \\
\text { anketirancev }\end{array}$ & 0 & 1 & 2 & $\overline{\mathrm{x}}$ & $\mathrm{SD}$ & $\begin{array}{c}\text { Friedmanov } \\
\text { test }\end{array}$ \\
\hline \multirow{2}{*}{$\begin{array}{l}\text { Ali ste v zadnjih šestih } \\
\text { mesecih v prho dali } \\
\text { namestiti zračnik za } \\
\text { nizek pretok, ki vodi } \\
\text { primeša zrak? }\end{array}$} & $\begin{array}{l}\text { pred } \\
\text { vplivanjem }\end{array}$ & 95 & $100,0 \%$ & $0,0 \%$ & I & 0,00 & 0,00 & $\chi^{2}=7,000$ \\
\hline & po vplivanju & 95 & $92,6 \%$ & $7,4 \%$ & 1 & 0,07 & 0,26 & $\mathrm{p}<0,01$ \\
\hline \multirow{2}{*}{$\begin{array}{l}\text { Ali ste v zadnjih šestih } \\
\text { mesecih vgradili ekološki } \\
\text { straniščni splakovalnik? }\end{array}$} & $\begin{array}{l}\text { pred } \\
\text { vplivanjem }\end{array}$ & 95 & $98,9 \%$ & $1,1 \%$ & 1 & 0,01 & 0,10 & $\chi^{2}=3,000$ \\
\hline & po vplivanju & 95 & $95,8 \%$ & $4,2 \%$ & 1 & 0,04 & 0,20 & $\mathrm{p}>0,05$ \\
\hline \multirow{2}{*}{$\begin{array}{l}\text { Ali ste v zadnjih šestih } \\
\text { mesecih preverili, ali } \\
\text { v stanovanju kje uhaja } \\
\text { voda? }\end{array}$} & $\begin{array}{l}\text { pred } \\
\text { vplivanjem }\end{array}$ & 95 & $31,6 \%$ & $68,4 \%$ & 1 & 0,68 & 0,46 & $\chi^{2}=3,000$ \\
\hline & po vplivanju & 95 & $10,2 \%$ & $89,8 \%$ & 1 & 0,89 & 0,42 & $p>0,05$ \\
\hline \multirow{2}{*}{$\begin{array}{l}\text { Ali ste v zadnjih šestih } \\
\text { mesecih tisto posodo, } \\
\text { ki ste jo pomivali ročno, } \\
\text { pomivali v pomivalnem } \\
\text { koritu, pod tekočo vodo } \\
\text { pa jo samo splaknili? }\end{array}$} & $\begin{array}{l}\text { pred } \\
\text { vplivanjem }\end{array}$ & 95 & $30,5 \%$ & $69,5 \%$ & 1 & 0,69 & 0,46 & $\chi^{2}=12,000$ \\
\hline & po vplivanju & 95 & $17,4 \%$ & $82,6 \%$ & 1 & 0,82 & 0,44 & $\mathrm{p}<0,001$ \\
\hline \multirow{2}{*}{$\begin{array}{l}\text { Ali ste v zadnjih šestih } \\
\text { mesecih zmanjšali rabo } \\
\text { čistil, pralnih praškov, } \\
\text { mehčalcev ali kozmetike? }\end{array}$} & $\begin{array}{l}\text { pred } \\
\text { vplivanjem }\end{array}$ & 95 & $33,7 \%$ & $66,3 \%$ & 1 & 0,66 & 0,47 & $\chi^{2}=13,762$ \\
\hline & po vplivanju & 95 & $15,5 \%$ & $84,5 \%$ & 1 & 0,84 & 0,43 & $\mathrm{p}<0,001$ \\
\hline \multirow{2}{*}{$\begin{array}{l}\text { Ali ste v zadnjih šestih } \\
\text { mesecih v straniščno } \\
\text { školjko metali stvari, ki } \\
\text { bi lahko zamašile odtok } \\
\text { vode ali zastrupile vodo? }\end{array}$} & $\begin{array}{l}\text { pred } \\
\text { vplivanjem }\end{array}$ & 95 & $77,9 \%$ & $22,1 \%$ & 1 & 0,22 & 0,41 & $\chi^{2}=3,556$ \\
\hline & po vplivanju & 95 & $86,1 \%$ & $13,9 \%$ & 1 & 0,14 & 0,38 & $\mathrm{p}<0,05$ \\
\hline \multirow{2}{*}{$\begin{array}{l}\text { Ali ste v zadnjih šestih } \\
\text { mesecih vgradili } \\
\text { individualni števec } \\
\text { za merjenje porabe } \\
\text { vode v stanovanju? }\end{array}$} & $\begin{array}{l}\text { pred } \\
\text { vplivanjem }\end{array}$ & 95 & I & I & I & I & I & I \\
\hline & po vplivanju & 95 & $85,3 \%$ & $12,6 \%$ & $2,1 \%$ & 0,13 & 0,33 & 1 \\
\hline
\end{tabular}


merjenimi metodami socialnega vplivanja, ki temeljijo na praktičnem pristopu lahko torej dosežemo dobro razumljivost in ozaveščenost, kar vodi v ustrezne premike tudi v praksi. Eden izmed ustreznih načinov je nedvomno implementacija metod socialnega vplivanja v izobraževalni sistem, saj so mladi tisti, ki so najbolj dovzetni za spremembe, hkrati pa predstavljajo najučinkovitejši medij za prenos tovrstnih idej na starejše.

\section{Viri in literatura}

Abrahamse, W., Matthies, E. 2013: Informational strategies to promote pro-environmental behaviour: Changing knowledge, awareness and attitudes. Environmental Psychology: An Introduciton. Chichester. Anketa o rabi vode v gospodinjstvu. Geografski inštitut Antona Melika ZRC SAZU. Ljubljana, 2010. Bell, P. A., Greene, T. C., Fisher, J. D., Baum, A. 2001: Environmental Psychology. Fort Worth.

Bolderdijk, J. W., Lehman, P. K., Geller, E. S. 2013: Encouraging pro-environmental behaviour with rewards and penalties. Environmental Psychology: An Introduciton. Chichester.

Bradley, A. J. 2010: A new definition of Social Media. Medmrežje: http://blogs.gartner.com/anthony_ bradley/2010/01/07/a-new-definition-of-social-media/ (10.10.2013).

Brehm, J. W. 1966: A Theory of Psychological Reactance. New York.

Burja, A. 2007: Vzemite manj, imejte več: zbirka namigov za neškodljivo življenje. Ministrstvo za okolje in prostor, Ministrstvo za zdravje, Urad Republike Slovenije za kemikalije. Ljubljana. Medmrežje: http://www.arhiv.mop.gov.si/fileadmin/mop.gov.si/pageuploads/publikacije/drugo/vzemite_manj_ imejte_vec_01.pdf (10.10.2012).

De Young, R. 1993: Changing behaviour and making it stick. The conceptualization and management of conservation behaviour. Environment and Behaviour 25-3. DOI: https://doi.org/ $10.1177 / 0013916593253003$

DuNann Winter, D., Koger, S. M. 2004: The Psychology of Environmental Problems. New York.

Festinger, L. 1957: A Theory of Cognitive Dissonance. Stanford.

Gardner, G. T., Stern, P. C. 2002: Environmental Problems and Human Behaviour. Boston.

Geller, E. S. 2002: The challange of increasing proenvironmental behaviour. Handbook of Environmental Psychology. New York.

Geller, E. S., Winett, R. A., Everett, P. B. 1982: Preserving the Environment: New Strategies for Behaviour Change. New York.

Kaplan, A. M., Haenlein, M. 2010: Users of the world, unite! The challenges and opportunities of Social Media. Business Horizons 53-1. DOI: https://doi.org/10.1016/j.bushor.2009.09.003

Kollmuss, A., Agyeman, J. 2002: Mind the gap: Why do people act environmentally and what are the barriers to pro-environmental behaviour? Environmental Education Research 8-3. DOI: https://doi.org/ $10.1080 / 13504620220145401$

Kreuter, M. W., Farrell, D., Olevitch, L., Brennan, L. 1999: Tailored Health Messages: Customizing Communication with Computer Technology. New York.

Mayfield, A. 2008: What is social media? Medmrežje: www.repromax.com/docs/113/854427515.pdf (10.10.2013)

Medmrežje 1: http://www.ekologicen.si (29.11.2010).

Medmrežje 2: http://www.life-income.si/template/flash/kviz.html (29.11.2010).

Messick, D. M., Brewer, M. B. 1983: Solving social dilemmas: A review. Review of Personality and Social Psychology 4.

O’Dell, J. 2011: The History of Social Media. Medmrežje: http://mashable.com/2011/01/24/the-historyof-social-media-infographic (10.10.2012).

Polajnar Horvat, K. 2012: Oblikovanje modela razvoja okoljske ozaveščenosti in okolju prijaznega vedenja. Geografski vestnik 84-2. 
Polajnar Horvat, K. 2015: Okolju prijazno vedenje. Georitem 26. Ljubljana.

Polič, M. 2002: Odnos do okolja, vedenjske in socialne pasti. Panika 7-1.

Ponovitvena spletna anketa o rabi vode v gospodinjstvu. Geografski inštitut Antona Melika ZRC SAZU. Ljubljana, 2010.

Schultz, P. W. 1999: Changing behaviour with normative feedback interventions: A field experiment on curbside recycling. Basic and Applied Psychology 21-1.

Skinner, B. F. 1953: Science and Human Behaviour. New York.

Spletna anketa o rabi vode v gospodinjstvu. Geografski inštitut Antona Melika ZRC SAZU. Ljubljana, 2010.

Staats, H. J., Wit, A. P., Midden, C. Y. H. 1996: Communicating the greenhouse effect to the public: Evaluation of a mass media campaign from a social dilemma perspective. Journal of Environmental Management 46-2. DOI: https://doi.org/10.1006/jema.1996.0015

Steg, L., Gifford, R. 2008: Social psychology and environmental problems. Applied Social Psychology: Understanding and Managing Social Problems. Cambridge.

Steg, L., Vlek, C. 2009: Encouraging pro-environmental behaviour: An integrative review and research agenda. Journal of Environmental Psychology 29-3. DOI: https://doi.org/10.1016/j.jenvp.2008.10.004

Thøgersen, J. 2005: How many consumer policy empower consumers for sustainable lifestyle? Journal of Consumer Policy 28-2. DOI: https://doi.org/10.1007/s10603-005-2982-8

Vlek, C. 2000: Essential psychology for environmental policy making. International Journal of Psychology 35-2. DOI: https://doi.org/10.1080/002075900399457

Vlek, C., Steg, L. 2007: Human behaviour and environmental sustainability: problems, driving forces and research topics. Journal of Social Issues 63-1. DOI: https://doi.org/10.1111/j.1540-4560.2007.00493.x

\section{Summary: The efficacy of social influence in environmental awareness and behaviour regarding water}

(translated by the author)

The concepts of encouraging environmental awareness and changing environmental behaviour are gaining recognition in current discussions and are the foundation of a sustainably-oriented society. People with their anthropocentric worldviews and materially intense activities degrade drinking water as a natural resource on a daily basis and profoundly affect its availability and quality with their mindset and activity. One of the possible solutions to this is to use social influence methods, which help change mentalities and behaviour. The article addressed the question to what degree the selected method-directed information and education, commitments, reminders and rewards-can be successful in supporting man's environmental protection tendencies and in changing behaviour regarding water.

There are several definitions of social influence, depending on the influence that a certain method has on behaviour (De Young 1993; Vlek 2000; Gardner and Stern 2002; Geller 2002). The research adopts a slightly modified Messick and Brewer (1983) strategy definition. It distinguishes between information strategies, which are used to change an individual's motivation, perception, knowledge and norms or level of awareness without adapting the external circumstances in which these decisions were made, and between structural strategies (Steg and Vlek 2009), which alter the circumstances in which behavioural decisions are made or in which the behaviour is realized (Messick and Brewer 1983; Steg and Vlek 2009). Information strategies can also be designated as soft measures and include education, reminders, predetermined goals, commitments, feedback, etc. On the other hand, structural strategies can be regarded as hard measures (Abrahamse and Matthies 2013), which require change in the technical area or in the incentive.

After a six-month period of implementing selected methods of social influence, the participants expressed a more positive attitude toward the environment and readiness for environmentally friendly behaviour than before the implementation of social influence; around a sixth $(14,7 \%)$ more people 
opted in favour compared to the period before the implementation of the social influence. The share of those who opted out was decreased by just over a twentieth (6.3\%). The Friedman test, which was used to determine the statistical significance of the differences in both measurements, indicated a statistically significant difference for the variable on water conservation. Directed information and education proved to be successful for strengthening knowledge, as the individuals expressed a notably higher level of knowledge of the studied contents after the social influence was implemented. It was also quite successful in strengthening the perceived behavioural control, which is the individual's own perceived ability to act in an environmentally friendly manner and their conviction that sufficient funds are available to perpetuate that behaviour. The reason for this is most likely in the notable emphasis that was placed on informing the participants using relatively simple and minor measures in the economy, which can be implemented to improve the state of the environment and which can also be performed by each individual with minimal effort without the need for any kind of additional funds or costs. Through this, the participants were able to achieve a significant shift in perceiving their own abilities and efficiency. The results also point to a change in their willingness to act in an environmentally friendly way, which indicates that the social influence methods encouraged the participants to act. Commitment also proved to be useful, as the participants reacted very positively to it. Another successful tool were the reminders; often times when they were posted, especially on Facebook, a lively debate on the topic followed. In contrast, rewards turned out to be less successful, as the participants of the personal survey, especially those who were uninterested, were not convinced by the incentive enough to take part in it. One of the reasons for this might be that the rewards were of an exclusively environmental protection nature and therefore could not draw in a wider circle of people who are less interested in environmental issues. We concluded that the internet is an efficient medium for introducing social influence methods. On one hand, it allows researchers to reach a relatively large number of people, while it also enables them to use social influence methods or strategies that are adjusted to each individual depending on their characteristics and needs. Using directed methods of social influence based on the practical approach can therefore be used to improve understanding and awareness, which can lead to the corresponding shifts in practice as well. One of the appropriate ways to achieve the goal of environmental awareness is undoubtedly to implement social influence methods into the educational system, since young people are most susceptible to change and are also the most effective in transferring such ideas to older people. 